\title{
Odontogenic Keratocyst: An Enigma
}

\section{INTRODUCTION}

Odontogentic Keratocyst (Primordial cyst) is a developmental odontogenic cyst arising from the primordial sheath. ${ }^{1,2}$ The term OKC was first coined by Philipsen in 1956. ${ }^{1-3}$ The cyst shows a different mechanism of growth and behavior than dentigerous and radicular cysts. Also, the lining epithelium of these cysts is different from that of OKC. . $^{2,3}$ It had been previously suggested that the cyst behaves like a neoplasm based on the locally aggressive behavior, histopathology and recurrence. The World Health Organization in 2017 has again classified OKC as a cyst as the evidence supporting the clonality is insufficient. ${ }^{4}$

OKC may occur in any age but is most common in the second and third decades of life with a slight male preponderance. ${ }^{1}$ It occurs most frequently in the posterior body and ramus of mandible. In this case report, we present a 16 year old male with OKC and impacted right mandibular second and third molars which had clinical and radiographic presentations of a dentigerous cyst.

\section{CASE REPORT}

A 16 year old male came to the department of Oral Medicine and Radiology with the chief complaint of swelling on right side of the face since 1 week. (figure 1) The swelling was primary in incidence, gradual in onset. He complains of limited mouth opening since 1 week. The swelling was larger in size 5 days back. The patient had taken antibiotics and analgesics since 1 week from a local chemist. There is history of pus discharge in the oral cavity 3 years back because of which he took the same medication.

The medical and past dental histories were noncontributory. Extra-oral examination revealed a solitary diffuse swelling of size $3 \times 4 \mathrm{cms}$ extending antero-posteriorly from line drawn $4 \mathrm{cms}$ inferiorly from the outer canthus of the eye to angle of the mandible and supero-inferiorly from a line drawn $3 \mathrm{cms}$ posteriorly from ala of nose to inferior border of mandible. (figure. 1) The skin over surface of the swelling appeared normal. There were no visible palpations present. No serosanguinous discharge was noted. The inter-incisal mouth opening was $24 \mathrm{~mm}$. (figure. 2) On palpation, the inspectory characteristics were confirmed. There was no local rise in temperature. Swelling was slightly tender, soft to firm in consistency, non-mobile, non-fluctuant, compressible but not reducible. No palpable pulsations were felt. There was no serosanguinous discharge on palpation. Intra-oral examination showed clinically absent 47 and 48 . (figure. 3 ) On soft tissue examination, obliteration of vestibule w.r.t 47 and 48 regions was evident. A diffuse oval swelling of size $7 \times 8 \mathrm{~mm}$ was evident w.r.t the alveolar mucosa of 47 and 48 which was reddish pink in color. On palpation, it was tender, soft in consistency, compressible but not reducible, non-fluctuant. Fine Needle Aspiration Cytology suggested a cystic content. (figure. 4)

Based on the clinical findings, a provisional diagnosis of dentigerous cyst w.r.t 47 and 48 was made. The differential diagnosis included Ameloblastoma, OKC, Adenomatoid Odontogenic tumor, Calcifying Epithelial Odontogenic tumor. Panoramic radiograph revealed a well-defined unilocular radiolucency measuring about $2 \times 4 \mathrm{~cm}$ with a scalloped outline seen in the right body and ramus of the mandible. (figure. 5) The radiolucency extended anteroposteriorly from the distal root of 46 to approximately $0.5 \mathrm{~cm}$ anterior to the posterior border of the mandible. 
Superoinferiorly, it extends from the middle third of the roots 31 to 37 upto the inferior border of mandible. Cone beam computed tomography coronal section showed a large cystic lesion measuring $19.8 \mathrm{~mm}$ x20.1 $\mathrm{mm}$ with lingual cortical plate perforation along with thinning of buccal cortical plate. (figure. 6)

Histopathology sections revealed sections showed hyper-orthokeratinised, convoluted, cystic lining overlying a loose, cellular and thin cystic capsule. The lining was uniformly 6-10 layered thick with cuboidal to columnar basal cells suggestive of orthokeratinized Odontogenic Keratocyst. (figure. 7) Hence, a final diagnosis of orthokeratinized OKC was given.

\section{DISCUSSION}

Odontogenic keratocyst (OKC) or Keratocystic odontogenic tumor (KCOT) is a locally aggressive entity which behaves both like a cyst and neoplasm.2 Small cysts are asymptomatic whereas patients with larger cysts may have symptoms of pain, swelling or pus discharge.1,3 Some cysts may grow up to a large size before being clinically detected. This may be attributed to the tendency of the cyst to grow in an anteroposterior direction without any evident bony expansion. ${ }^{1,3,5}$

Radiologically, most cysts are unilocular being a welldefined radiolucency with a corticated border. Larger lesions may often appear multilocular with curved internal septae giving the lesion a "soap bubble" or "honey comb" appearance similar to ameloblastoma. ${ }^{5}$ Advanced imaging such as Computed Tomography can determine the extent and location of the lesion. CBCT is preferred over CT due to its low cost, less radiation dose, easy availability and a shorter acquisition time. $^{6}$

The histological features include mostly a thin parakeratinized epithelium (six to eight cells thick). Less frequently, an orthokeratinized epithelium can also be seen. The cystic lumen may contain a cheesy material which is microscopically keratin or a serum transudate. Orthokeratinized OKC are more aggressive than their parakeratinized counterparts.37

The differential diagnosis of the lesion includes ameloblastoma, dentigerous cyst, traumatic bone cyst, lateral periodontal cyst. ${ }^{8}$

The diagnostic features of Ameloblastoma are a painless slow growing swelling mostly in the mandibular posterior teeth region. Mobility of the involved teeth, root resorption and paraesthesia may be present. ${ }^{8}$

The present case is quite similar to a case of dentigerous cyst owing to the clinical and radiologic features. However, histopathology can lead to the final diagnosis.

Traumatic bone cyst presents usually with a history of trauma. Also, it is detected in radiographs during routine examination. ${ }^{8}$

In the present case, although the clinical and radiologic features suggested the presence of dentigerous cyst, histopathological features were conclusive of an orthokeratinized OKC which makes it a rare and interesting case.

The treatment includes surgical curettage, resection or marsupialization., ${ }^{1,6,7,9} \mathrm{OKC}$ has a propensity to recur after treatment. iRecurrence rates have been reported to be 5 to $62 \%$ which is probably due to the incomplete removal of the cystic lining or the satellite cysts formed following the surgery. The management procedures such as peripheral ostectomy, use of Carnoy's solution, decompression treatment with the use of polyethylene drainage tube have been proven useful. ${ }^{1,9}$

\section{CONCLUSION}

To conclude, most common cyst in the impacted third molar region is dentigerous cyst. Other cysts according to the age group can be OKC and tumors such as AOT. Clinicians ought to be very careful as only thorough clinical, radiological and histopathological can clinch the correct diagnosis.

\section{REFERENCES}

1.Neville B., Douglas D.D., Carl C., Chi A. Odontogenic cysts and tumors Oral and Maxillofacial Pathology $4^{\text {th }}$ ed.

2. Shafer's textbook of Oral Pathology $8^{\text {th }}$ ed.

3. Shear M., Cysts of the Oral Regions ${ }^{\text {th }}$ ed.

4. Chaudhary S, Sinha A, Barua P, Mallikarjuna R, Keratocystic odontogenic tumour (KCOT) misdiagnosed as a dentigerous cyst. BMJ Case Rep 2013: 1-5.

5. White S, Pharoah M. Oral Radiology Principles and interpretation $7^{\text {th }}$ ed.

6. Berberoğlu HK, Çakarer S, Brkić A, Koseoglu BG, Aydil BA, Keskin C. Three-dimensional cone-beam computed tomography for diagnosis of keratocystic 
odontogenic tumours; Evaluation of four cases. Med Oral Patol Oral Cir Bucal. 2012 Nov 1;17 (6):100o-5

7. Chaudhary S, Sinha A, Barua P, Mallikarjuna R. Keratocystic Odontogenic Tumor (KCOT) misdiagnosed as a Dentigerous cyst. BMJ Case Rep 2013:1-5.
8. Norman K. Wood, Paul W. Goaz, Differential Diagnosis of Oral and Maxillofacial lesions, 5 th ed.

9. Motwani MB, Mishra SS, Anand NM, Degwekar SS, Bhowate RR. Keratocystic Odontogenic Tumor: Case Reports and Review of Literature. JIAOMR 2011; 23(2): $150-4$.

Source of support: Nil, Conflict of interest: None declared

Cite this article as:

Garg A, Singh K, Jain M, Khan M. Odontogenic Keratocyst: An Enigma. Int

Healthcare Res J 2018;2(5):111-114. doi: 10.26440/IHRJ/02_05/189

\section{AUTHOR AFFILIATIONS:}

1. MDS, Senior Consultant, Max Hospital, New Delhi

2. MDS, (Oral Medicine and Radiology)

3. Senior Lecturer, Department of Oral Medicine and Radiology, J N Kapoor DAV(C) Dental College, Yamuna Nagar, Haryana

4. MDS, Senior Resident, GTB Hospital, New Delhi

\section{Corresponding Author:}

Dr. Kesari Singh

MDS (Oral Medicine and Radiology)

B-27 Delta 1st, Silver Oak Estate

Greater Noida U.P 201308
For article enquiry/author contact details, e-mail at: manuscriptenquiry.ihrj@gmail.com

\section{LEGENDS}

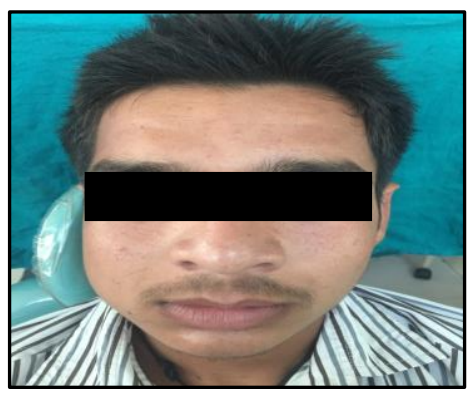

Figure 1. Extra-oral swelling on right side of the face

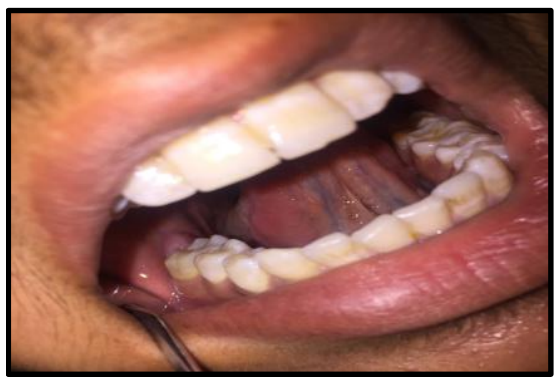

Figure 3. Intra-oral examination reveals absent 47 and 48

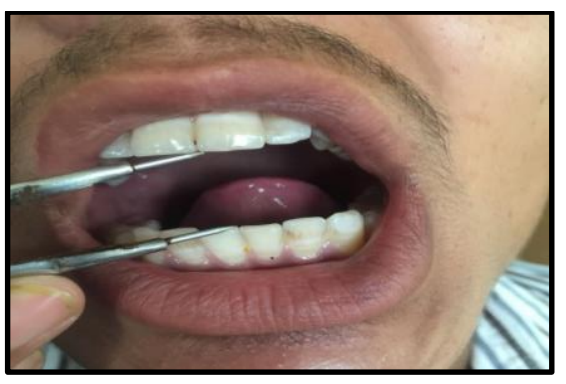

Figure 2. Inter-incisal opening $=\mathbf{2 4} \mathrm{mm}$

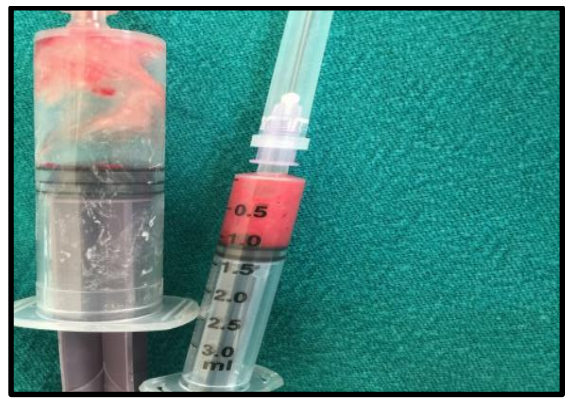

Figure 4. FNAC reveals a cystic content 


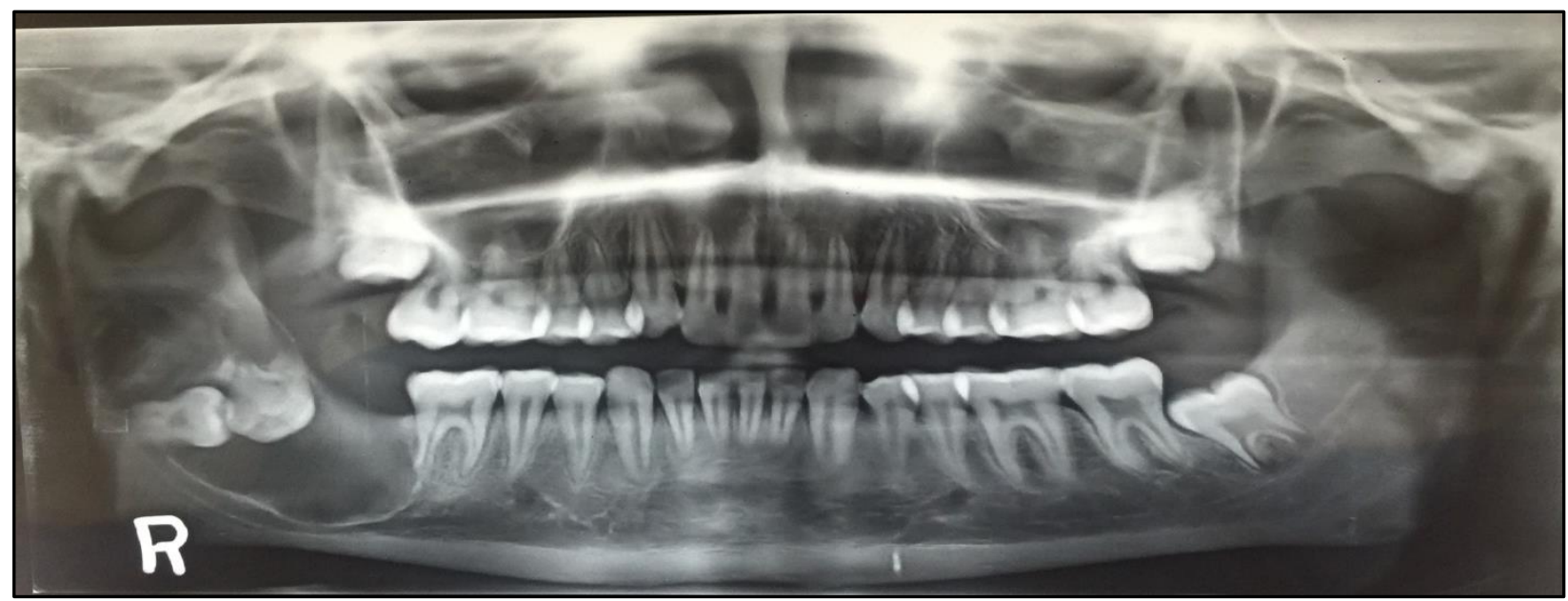

Figure 5. Panoramic radiograph reveals a well-defined unilocular radiolucency measuring about 2x4 cm with a scalloped outline seen in the right body and ramus of the mandible.

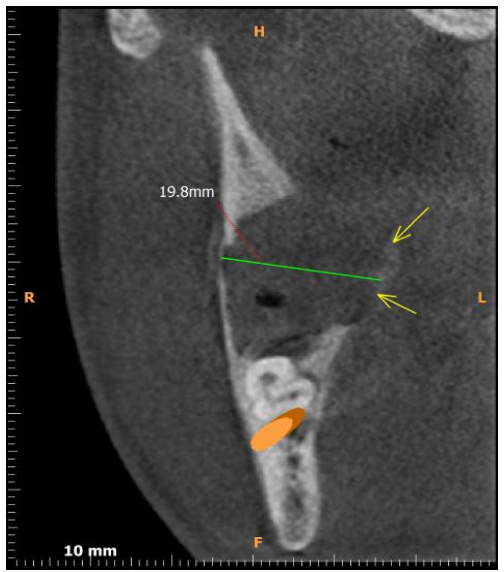

Figure 6. Coronal section of CBCT shows a large cystic lesion measuring $19.8 \mathrm{~mm}$ x20.1 $\mathrm{mm}$ with lingual cortical plate perforation along with thinning of buccal cortical plate.

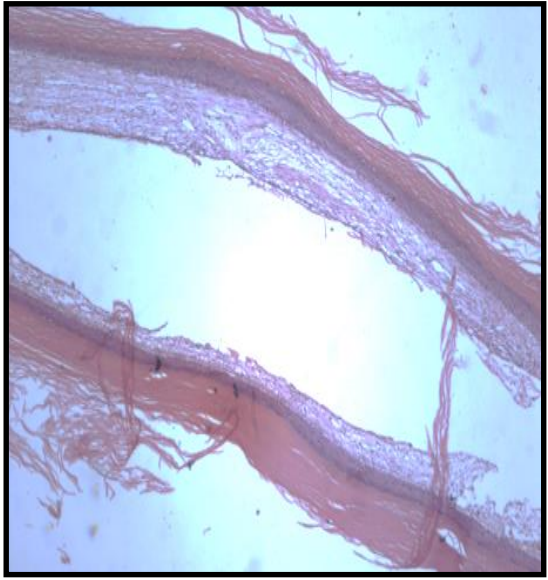

Figure 7. Histological section shows hyperorthokeratinised, convoluted, cystic lining overlying a loose, cellular and thin cystic capsule is seen. The lining is uniformly 6-10 layered thick with cuboidal to columnar basal cells 